Xalapa musical

ESBOZDS

\section{Alfonso Colorado}

\section{La primera vez que se oye una or-} questa es una sacudida: la sedosidad de la cuerda, el brillo de los metales, la dulzura de las maderas, lo variado de los timbres, la potencia de una coda...

\section{DESTELLQS}

ué son 90 años de una orquesta para una perso-

na? Una abstracción, un océano de conciertos que se superponen y diluyen en la memoria, donde solo algunos brillan sin caducidad. En los años noventa recuerdo una impresionante Consagración de la primavera dirigida por Jorge Mester, la primera vez que vi que un director podía cambiar el sonido de una orquesta; a un Luis Herrera de la Fuente octogenario dirigiendo con vigor la Heroica. En vísperas del Festival Europalia 1993, la osx tocó durante varias semanas el repertorio que llevaría a Holanda, Bélgica y Luxemburgo, que fue mejorando hasta que en el concierto de despedida se oyeron versiones antológicas de Sensemayá y El pájaro de fuego en una noche de euforia en el Teatro del Estado. A esta memoria se han integrado conciertos dirigidos por Lanfranco Marcelletti Jr., como Las bodas de Fígaro en 2017 o, en 2018, Música para Praga 1968 de Karel Husa, o la Sinfonía n.o 11, El año 1905, de Dimitri Shostakovich, vívidas descripciones de masacres de civiles y del imperio de la violencia, ecos que resuenan en nuestra cotidianidad. Son memorables también los conciertos dirigidos anualmente desde 2014 por Rafael Palacios, quien utiliza criterios retóricamente informados en obras barrocas y del clasicismo.
La primera orquesta que oí fue una danzonera en el parque Zamora, en Veracruz: piano, sección de cuerdas y de alientos, timbales, su cadencia era cálida y envolvente. A principios de los años ochenta, durante un paseo familiar en Los Lagos se oyó música a lo lejos; mi madre decidió seguirla y llegamos al teatro al aire libre del IMss. La orquesta apenas cabía en el escenario, los músicos vestían de blanco, dirigía Herrera de la Fuente. Tocaban la Pequeña serenata nocturna y el Huapango, que desconocía. No es el mero paso del tiempo lo que ha cambiado el orden de las cosas. Aquellas tranquilas noches de verano se asentaban sobre un sistema de bienestar que incluía la cultura; por ello el IMss tenía teatros en todo el país. El Estado sostenía librerías, salas de cine y bibliotecas públicas de primera (la Biblioteca de la Ciudad lo era); tenía un canal de televisión, el 13, donde se transmitían cosas como la integral de las sinfonías de Beethoven desde Viena, dirigidas y comentadas por Leonard Bernstein. La iniciativa privada participaba en esto; por ejemplo, la televisora dominante tenía un canal cultural que presentaba conciertos, documentales, coloquios; las compañías discográficas contaban con una división de música clásica; había editoriales que se dedicaban exclusivamente a publicar colecciones de clásicos literarios y musicales en tiraje masivo para su venta en supermercados. Esto se cimentaba sobre cierta estabilidad económica pero no era lo único; aquel gobierno autoritario y antidemocrático mantenía parcialmente, a pesar de todo, el pacto social originado décadas atrás, que trataba de satisfacer las necesidades básicas de la mayor parte de la población. No es casualidad que entonces la mejor educación básica y media fuese la pública, a la que aspiraban desde los más pobres hasta los más ricos, impartida en escuelas que integraban, no sin dificultades, a todas las clases. El consenso compartido por el Estado y la sociedad comenzó a resquebrajarse a principios de los años ochenta; en el campo llevaba roto por lo menos dos décadas.

El cine de la Época de Oro incorporó a menudo la música clásica pero en las matinés del cine Xalapa en los años setenta -Viruta y Capulina, El Santo, Chabelo y Pepito- era de otro tipo. Eran las caricaturas de la TV las que incluían fragmentos de obras de Mendelssohn, Rossini, Schubert...; tenían por lo menos veinte años de haberse creado, pero antes de internet los productos culturales no caducaban tan rápido. La primera vez que oí el Concierto de Brandenburgo n.o 3 fue en el comercial de un rancho porcino; los anuncios estuvieron detrás de mis primeras audiciones: el 


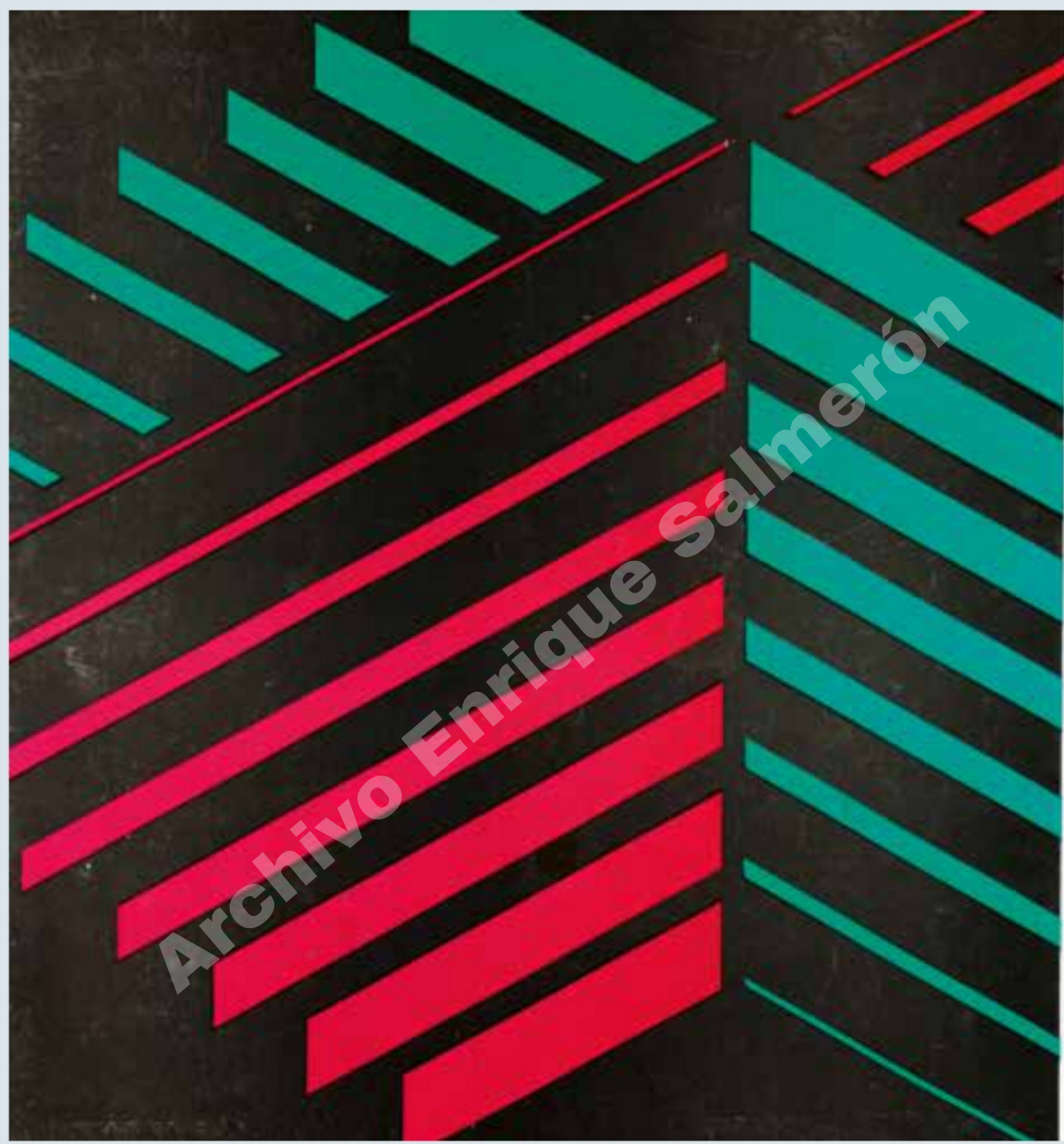

EUROPALIA 93
MEXICO

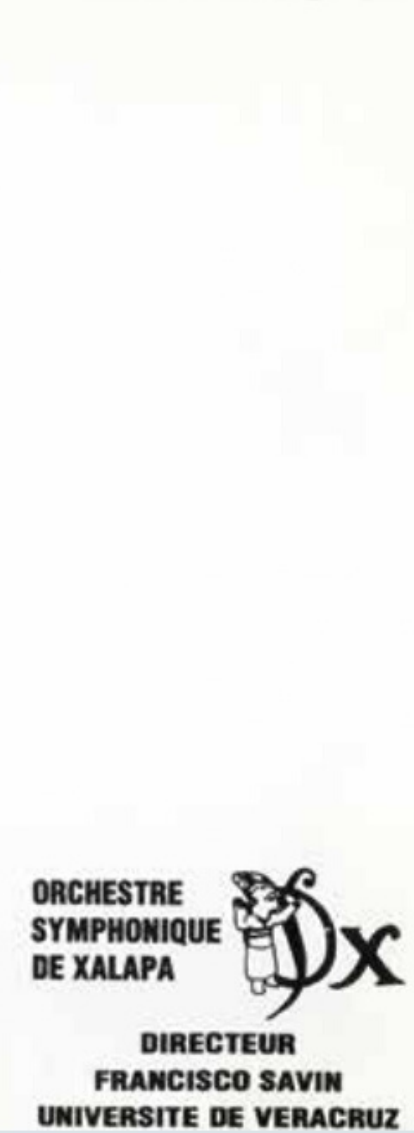

Portada del programa de Europalia, 1993. Imagen cortesía de Enrique Salmerón.

Capricho español (quesos), Carmina Burana (coches), Cuadros de una exposición (alfombras), la Sinfonía española (cigarros). En la era de los mass-media ¿̇podía ser de otra manera? Para mi generación las caricaturas fueron la primera escuela melómana, tardé años en disociarlas de lo que escuchaba en el recinto musical (todavía a veces hacen un guiño). Aquel primer concierto al aire libre no fue una iniciación, el rock y el blues eran irresistibles. Hacia 1990 me encontré de nuevo con la osx. La primera vez que se oye una orquesta es una sacudida: la sedosidad de la cuerda, el brillo de los metales, la dulzura de las maderas, lo variado de los timbres, la potencia de una coda ... es el orden en la diversidad.

A los conciertos en el Teatro del Estado iba toda la Facultad de Música. Maestros y estudiantes, vestidos del diario, leían la partitura, reían con los errores, los comentaban en voz alta e incluso los abucheaban, caldeando el ambiente (tal y como hacía el público en el
París de Berlioz). La programación era más modesta que la de ahora pero nadie faltaba. La comunidad musical ya no asiste en pleno a los conciertos de la osx, la vida artística, cultural y académica local se ha ampliado, dispersando al público y la Facultad de Música tiene una agenda variada (cursos, conferencias, conciertos especiales). Otras circunstancias influyen en la atomización; aquella era una ciudad pequeña cuyo radio era abarcado efectivamente por el Teatro del Estado; ahora carece de límites, las zonas nuevas son unidades aisladas fuera de la cuadrícula urbana (a menudo con una sola vía de acceso y salida) y el transporte público apenas existe. Tlaqná es un lugar espléndido, aunque para quien no tiene coche es complicado volver a casa tras el concierto. A pesar de todo, el público no universitario va en aumento, tal es la demanda de música.

Hay rituales en el interior de la osx que dejan una marca indeleble en el profano, como la marcha fúne- 


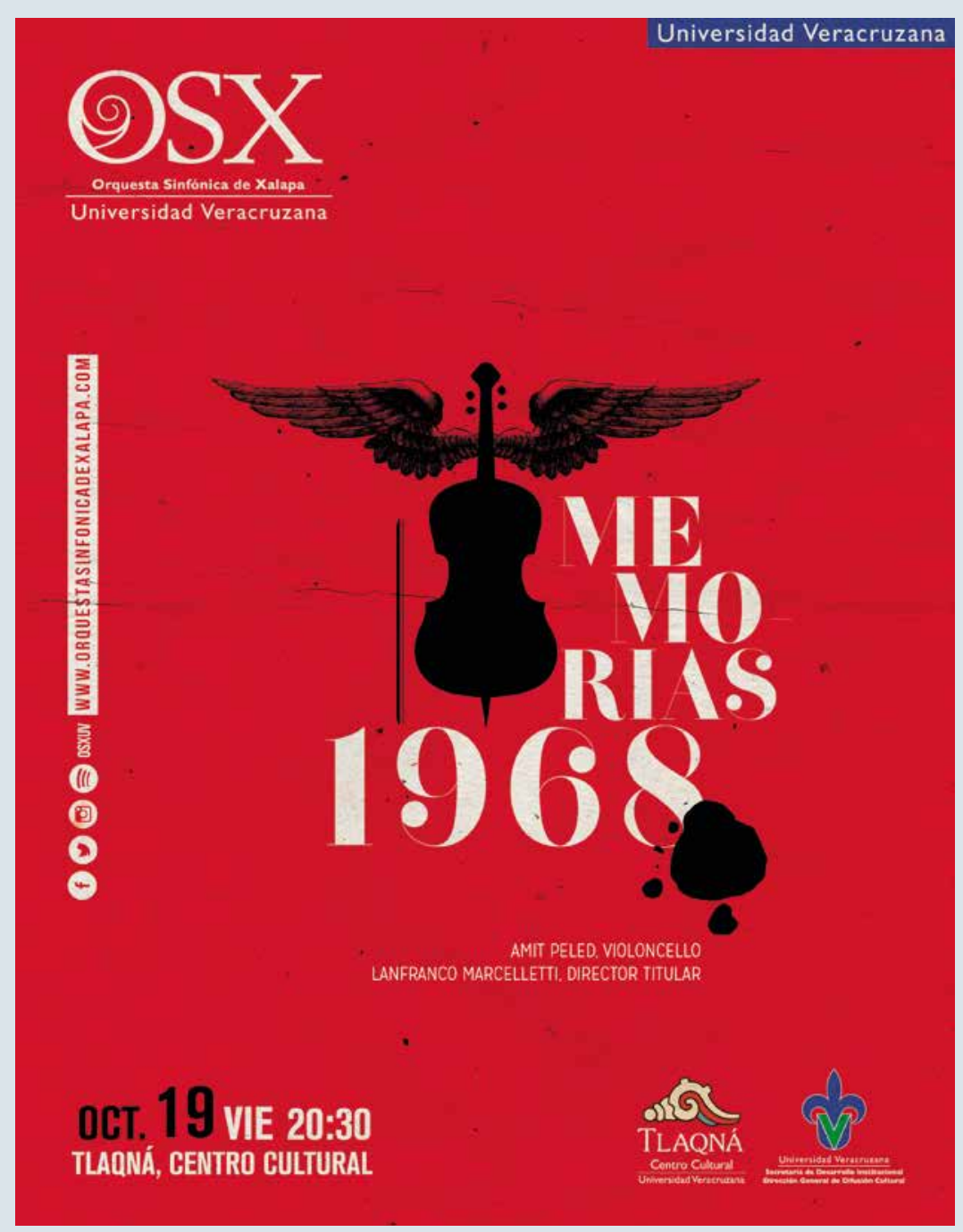

Diseño: Sinsuni E. Velasco Gutiérrez.

bre de la Heroica ante el féretro de un miembro de la orquesta cuando fallece; las cosas que ocurren tras bastidores forman parte de su tradición y matizan la interpretación cada ocho días. Antes de un concierto hay músicos que apenas están nerviosos mientras otros no pueden disimularlo, sobre todo si tocarán un solo. Es notorio el entusiasmo del novato, que decrece concierto a concierto. Escuchar un ensayo permite observar la edificación de la obra, y cuando no se solucionan por completo ciertas carencias aumenta la expectación del concierto. El público tiene sus rituales, como aplaudir a la mitad de una pieza con sincero entusias- mo (algo aceptable antes de que el concierto adquiriera un carácter litúrgico) o aunque todavía el director no ha bajado la batuta, lo que interrumpe el precioso silencio que forma parte de la obra. La memoria guarda conciertos con metidas de pata, cosas chuscas, sorpresas tristes (el fallecimiento de algún miembro de la orquesta pocas horas antes), algún accidente sin consecuencias... Que cada quien evoque sus recuerdos al respecto.

La fonoteca es una valiosa guía, pero hay detalles que ni la mejor tecnología ni las mejores grabacio- nes pueden dar. El proceso ideal, me parece, es escuchar la obra en grabaciones y después en vivo, no una cosa sin la otra. ¿De qué manera conocerla si no se oye varias veces? ¿Cómo aquilatar una ejecución si no es comparándola con la tradición interpretativa? Sin embargo, por muy notable que sea la Sinfonía fantástica con Eduard van Beinum y la Orquesta del Concertgebouw de Ámsterdam (Decca, 1951), en cualquier parte del mundo, para un melómano que tenga a su alcance una orquesta, la referencia será la cadena de interpretaciones locales, como la de la osx el 26 de enero de 2018, contrastando sus variaciones se conocerán mejor obra y orquesta. Una temporada es un curso. En la era de internet oír música es más fácil que nunca; oír una orquesta es, como desde hace siglos, un privilegio.

En Xalapa hay muchas vías de acceso a la música clásica. Los conciertos en Xallitic, el Palacio Municipal o la Catedral han atraído a un público que nunca iría a una sala de conciertos. Cuando solo se podía oír una obra teniendo un disco o grabándola en un cassete (de todas maneras había que conseguir el disco), Radio uv ponía al alcance un acervo que ampliaba el repertorio de la sala de conciertos, lo que compensaba el deficiente sonido en AM. Guillermo Cuevas se distinguía de otros locutores porque no solo consignaba el compositor y la obra sino sus movimientos, su lugar y fecha de composición, la orquesta y el director, la duración y otros detalles que mostraban que la música no se limitaba al sonido; también en Radio UV Alejandro Vázquez Romero tenía un programa que relacionaba música y literatura. En la preparatoria Oficial в había una materia optativa de música clásica. 
Un vecino, investigador de la uv, escuchaba sinfonías, conciertos y óperas (que gentilmente me grababa); mi hermana, estudiante en la Facultad de Música, ensayaba en casa. La Uv permea de muchas maneras la vida cotidiana en Xalapa, a la que convierte en un aula.

La osx es un recordatorio de que estamos circunscritos por el tiempo y por una generación. Quizá ya no queda nadie que la haya escuchado dirigida por su fundador, Juan Lomán (1929-1945) y cada vez hay menos personas que habrán oído a Limantour en su primer periodo (1944-1952) o a Ximénez Caballero (1952-1962). Nunca oí a Herrera (1975-1984) o a Diemecke (1986-1987) como titulares, apenas leí notas de Juan Vicente Melo. Fui un asistente regular entre 1991 y 1995 , durante el tercer periodo de Savín (1990-2001) a quien muchos escuchas actuales no oyeron; en pocos años aquella osx me dio las bases para sopesar otras orquestas en otros lugares. El 8 de noviembre de 2013 entré por vez primera en Tlaqná con el mismo asombro que todavía provoca en quienes asistíamos al Teatro del Estado; aunque la acústica de la nueva sala no es perfecta (algo difícil de conseguir) es mucho mejor que la de su anterior sede. Aquel día escuché la Sinfonía $n .^{\circ}$ 1 de Sibelius y el Concierto para dos pianos de Poulenc con Diana Castro y Jan Bratoz. La osx es otra orquesta y la misma. A veces, por un acto reflejo, veo a atrilistas (Kalarus, Guzmán, Saldívar) con quienes conocí el repertorio canónico. De esa tradición musical, soterrada pero firme, forman parte grupos como el Taller de Ópera del Teatro del Estado (creado por Olga Baldassari), la Orquesta de Cámara de la Universidad
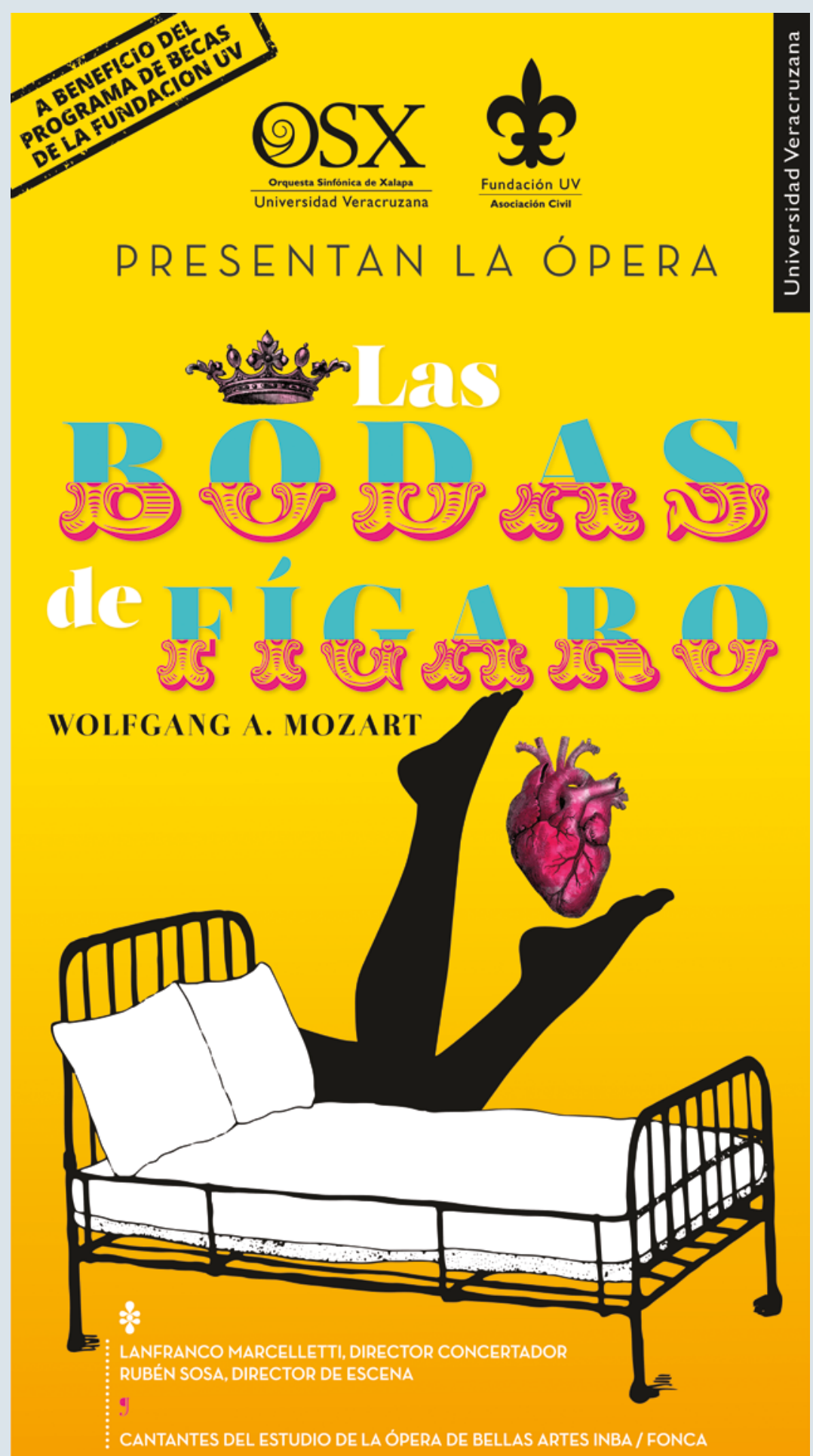

NOVIEMBRE 2017

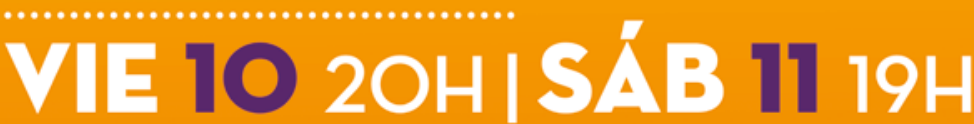

TLAQNÁ, CENTRO CULTURAL | BOLETOS EN TAQUILLA PRECIOS \$350. $\$ 400 . \$ 550 . \$ 600$

Diseño: Sinsuni E. Velasco Gutiérrez. 
(dirigida por Rino Brunello), el Cuarteto Clásico (dirigido por Francisco Lomán y después por Ángel Ruiz, violinistas de la osx), el Ensamble Clásico de Guitarras, el Trío Varsovia, la Coral Infantil de Xalapa (fundada por María Luisa Domínguez), La Pequeña Cantoría (fundada por Ana Elgarte), los Recitalistas de la UV y los ensambles que los miembros de la orquesta han formado. La temporalidad define a directores, músicos, público. La osx, como institución, no solo quiere decir una infraestructura estable sino que en nuestro lugar estuvo alguien antes y lo estará después, que la orquesta nos sobrevivirá. Esta es la realidad que trata de englobar la palabra tradición.

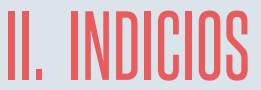

El primer tercio del siglo $\mathrm{xx}$ en Veracruz fue agitado: la huelga de Río Blanco, el huracán de la Revolución, el movimiento inquilinario en el puerto de Veracruz, la reforma agraria ( $y$ la violenta respuesta de los latifundistas), el asesinato de obreros en la fábrica de San Bruno y otros hechos cuyo eco todavía resuena. Los gobiernos posrevolucionarios impulsaron un proyecto modernizador cuyo símbolo más visible ahora es el Estadio Xalapeño, inaugurado bajo el gobierno de Heriberto Jara (1924-1927). En los gobiernos de Adalberto Tejeda (1920-1924, 1928-1932) y Gonzalo Vázquez Vela (1932-1935) se impulsó la creación de escuelas normales regionales, que incluían pensión para los alumnos, la mayoría hijos de campesinos; se establecieron jardines de niños en centros de trabajo y escuelas de alfabetización para adultos. Este proyecto acusadamente social tenía una vertiente educativa, cultural y artística. El Estadio Xalapeño fue punta de lanza en varios sentidos,
En septiembre de

1930 el gobernador

declaró que consi-

deraba al arte como

instrumento de lu-

cha social. Todo esto

está por estudiarse,

lo que parece claro

es que detrás del

surgimiento de la

osx no hay actuación

solo de algunas per-

sonas sino de fuer-

zas sociales en una

época convulsa.

como el cinematográfico (así lo ha documentado la investigadora Elissa Rashkin) con la película que Atanasio D. Vázquez rodó sobre su construcción, que está perdida. Con Jara los estridentistas proyectaron un programa editorial para consumo popular. Tejeda en persona negoció en la capital que el 20 por ciento del impuesto federal se destinara a educación, no a la construcción de caminos. Bajo su gobierno se creó en 1924 el Departamento Universitario y, en 1926, con Jara, se puso la primera piedra de la Universidad Veracruzana (que no se inauguraría hasta 1944). Muchas de estas iniciativas fueron efímeras o limitadas pero desencadenaron la movilización social. Vázquez Vela promulgó en Veracruz una nueva ley de educación, modernizadora e inclusiva. Lázaro Cárdenas lo nombró secretario de Educación Pública (19351939). Vázquez Vela promovió la creación en 1935 de una oficina encargada de los libros de texto gratuitos, antecedente de la instituida en 1959; asimismo jugó un papel clave en la creación del Instituto Politécnico Nacional (1936) y el Instituto Nacional de Antropología e Historia (1939). Tanto en la reforma de 1934 al artículo tercero constitucional, que postuló una educación socialista, como en la proliferación de escuelas rurales en el país entre 1935 y 1940 , el antecedente fue el laboratorio social de Veracruz.

Esos movimientos sociales tenían una dimensión específicamente musical. Algunos elementos provenían del régimen porfirista (las becas al extranjero para músicos, la creación de orquestas típicas en todo el país en 1884 y en Veracruz la de la Banda de Rurales en 1886, antecedente lejano de la osx) pero los cambios fueron drásticos. En 1926, con Jara, se creó el Departamento de Cultura Estética Popular, que relanzó la creación de orquestas típicas (y que el gobierno de Tejeda fomentó específicamente entre las organizaciones obreras). El gobernador era un melómano (tocaba el chelo), pero su interés personal no alcanza para explicar la fundación en 1929 de la osx; es posible que el hecho fuera un hito en una cadena de iniciativas culturales. Por algo en septiembre de 1930 el gobernador declaró que consideraba al arte como instrumento de lucha social. Todo esto está por estudiarse, lo que parece claro es que detrás del surgimiento de la osx no hay actuación solo de algunas personas sino de fuerzas sociales en una época convulsa. De ser así, uno de los objetivos de la política del Estado posrevolucionario entre 1920 y 1930 -que las clases populares accedieran a la (llamada) alta cultura- habría tenido un antecedente en Veracruz, donde la vida musical fue intensa desde el siglo XIX (como lo han mos- 


\section{CUARTA SERIE DE CONCIERTOS 1993}

PROGRAMA VI

* DE LA OPERA I PURITANI
ARIA DEL ACTO I. "ah! per sempre io ti perdei. ..
$\quad$ BELLINI

I N T E R M E D I O

\section{SINFONIA No. 1 EN RE MAYOR TITAN}

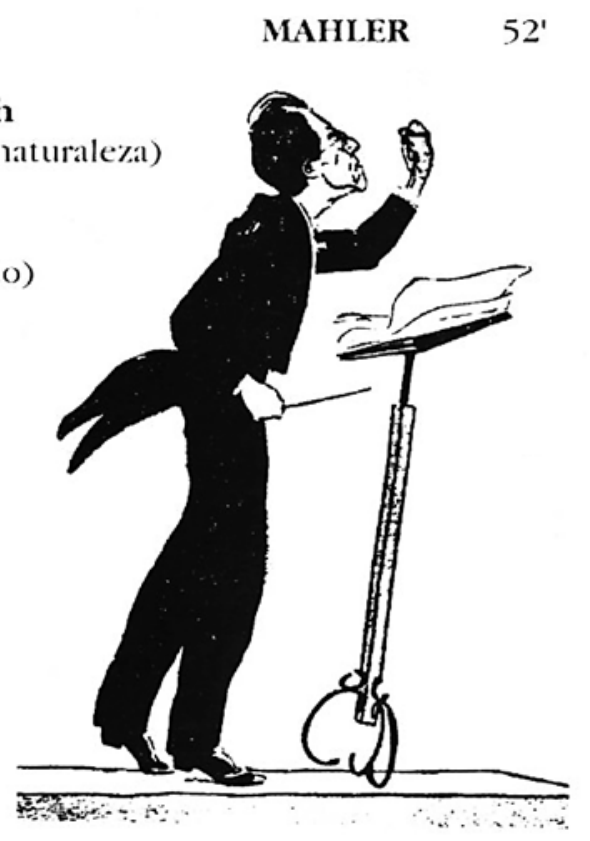

Langsam. Schleppend inanfang sehr gemälich

(Lenta y prolongadamente, como un sonido de la naturaleza)

Kräftig bewegt, dochnichtzuschnell

(Poderosamente agitado, pero no demasiado rápido)

Feierlich und gemessen, ohne zu zchleppen

(Solemne y mesurado, sin rezagarse)

Stürmich bewegt

(Tempestuosamente agitado)

\section{DIRECTOR TITULAR FRANCISCO SAVIN}

** Estreno en México

* Estreno en Xalapa

\section{DICIEMBRE 3}

trado las investigaciones de Julieta González y Raquel Velasco) pero cambió la extracción social del público al tiempo que la música orquestal pasó a ocupar el lugar de la ópera. El actual centro de la ciudad (el Estadio Xalape- ño, el IMSs con su teatro, la Zona Universitaria, Los Lagos) es un símbolo del pacto social que establecieron los primeros regímenes posrevolucionarios con la sociedad, aquel que se rompió sin que lo sustituyera un nuevo acuerdo.
1926, dos fotos de Atanasio D. Vázquez (figura rescatada por Rashkin). Una de abril, durante una gira del diputado Eduardo Cortina por Zongolica; afuera de una casa con piso de tierra y techo 


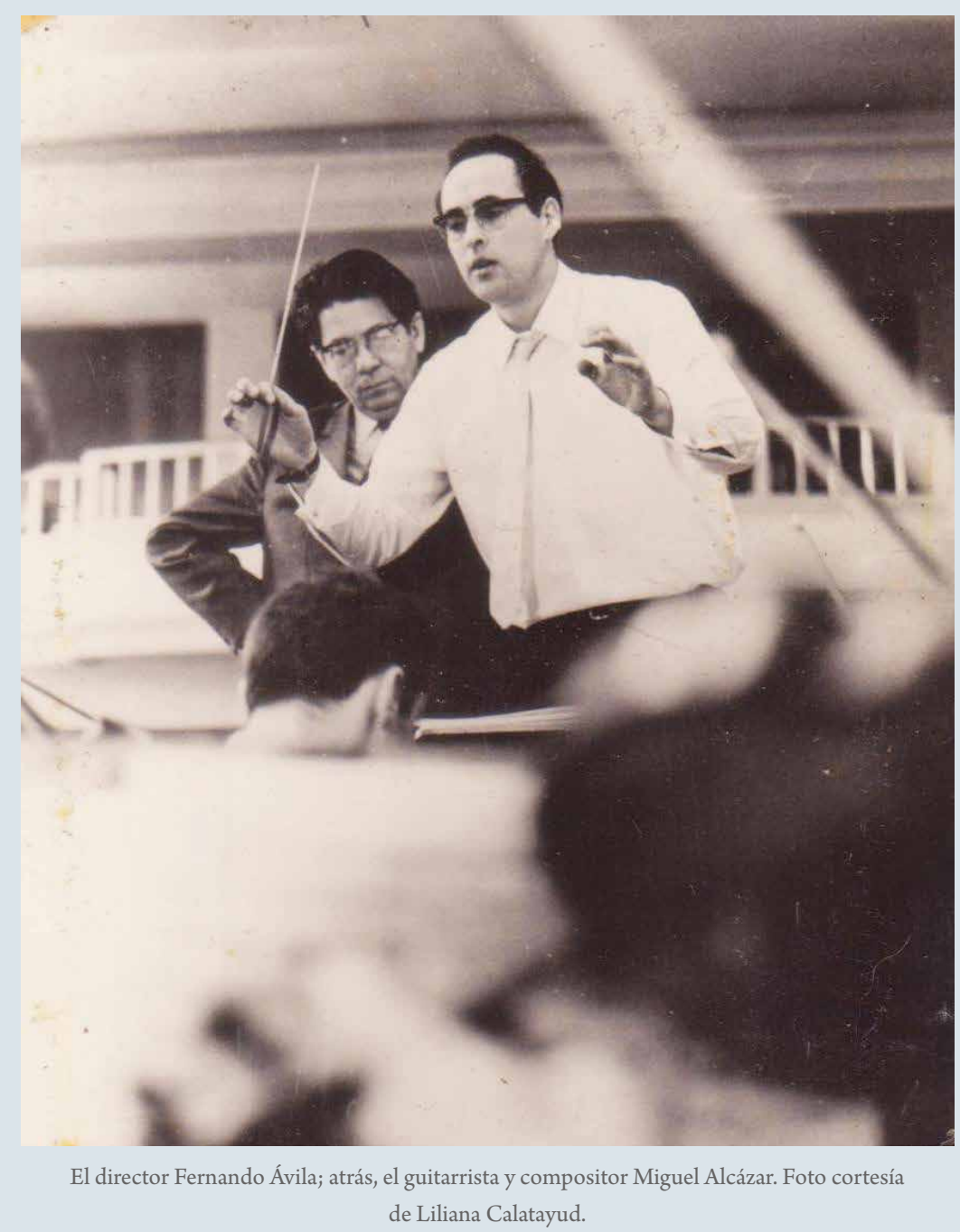

de palma se ve a una mujer famélica y a un niño con ropa sucia junto a los cuales dos músicos, uno descalzo y otro con huaraches, tocan la guitarra; los escuchan en silencio el diputado y todos los asistentes. Otra es del 5 de junio, de la Orquesta Típica Estudiantil Heriberto Jara: cuerdas (violines, violas, chelo, contrabajo) acompañadas de guitarras y mandolinas. El paraninfo del Colegio Preparatorio de Xalapa luce lleno en el concierto organizado por el Departamento de Cultura Estética Popular, sostén de esa orquesta que incluye a mujeres. Ambas fotos son un indicio del lugar que ocupaba la música en la cultura política en los años veinte. En la primera el evento se subordina, momentáneamente, ante ella; en la segunda se aprecia el resultado de la gestión del Estado. La música tocada es tradicional y popular pero entonces su convivencia con la clásica era mayor (los fundadores de la osx provenían de aquellos ámbitos) y el nuevo régimen nacional alentaría la síntesis de ambas. Estos hechos forman parte de un proyecto político, implementado no sin oposición; no es gratuito que el régimen de Jara haya cerrado las escuelas religiosas y que proyectara realizar una serie de murales en el Palacio $\mathrm{Mu}$ nicipal, lo que quedó trunco cuando Calles lo desalojó del poder en 1927; no es casualidad que el gobierno de Cárdenas vindicara estas iniciativas, renovadas por el régimen de Tejeda, y las aplicara como política de Estado.

Durante el siglo xIX y la primera mitad del xx la música clásica fue prerrogativa de las elites urbanas veracruzanas pero la osx cambió gradualmente ese panorama; así, en 1954, visitó la mitad de los municipios del Estado, una proeza entonces y ahora. La integración de la orquesta en la UV en 1975 cambió definitivamente la balanza; esto se nota al comparar dos de los eventos musicales más importantes realizados en Xalapa en toda su historia: en 1959, el Segundo Concurso Internacional de Violonchelo Pablo Casals y el Festival Pablo Casals se realizaron gracias a los esfuerzos de un comité internacional, del gobierno federal, estatal y municipal, pero no habrían bastado; el apoyo de la elite xalapeña fue decisivo, como lo ha señalado Enrique Salmerón. Ya no fue así en 2018, en el Festival Internacional de Piano Esperanza Cruz (que incluyó una academia y un concurso de piano), que trajo a Xalapa a Philippe Entremont y cuya base logística fue la infraestructura cultural pública (el Fondo Nacional para la Cultura y las Artes, la Universidad Veracruzana) sumada a las redes internacionales de la pianista Citlalli Guevara, creadora del evento. Desde 1975 la música sinfónica es parte de la formación que la UV ofrece a los estudiantes y a la sociedad gracias a una entrada que cuesta 80 pesos frente a los 500 que puede costar en otras partes del país. Razones históricas y económicas influyen para que en Xalapa los conciertos de la osx sean un evento cultural antes que uno social.

La osx también se ha acercado a un pequeño sector en el otro extremo del espectro social, el público especializado, que demanda música contemporánea. 
Tan solo en el periodo 2016 2019 se han interpretado obras de compositores de varios países y generaciones como Frank Proto, Gustavo Larrea, Roberto Sierra, Nathan Daughtrey, Aldemaro Romero, Daniel Binelli, David Amram, Paul Creston, Jonathan Dove, Eduardo Diazmuñoz, Eugenio Toussaint, Marlos Nobre, John Adams, Ödon Partos, Eduardo Gamboa, Giancarlo Castro, Cristina García, Manuel Torres, Rolando Ángel, Pablo Teutli, Tonatiuh Vázquez, Donald Harrison, Alejandro Basulto, Raúl Ladrón de Guevara, Hermilio Hernández, Eduardo Ángulo, Hebert Vázquez, Ryszard Siwy, Armando Lavalle, Ney Rosauro, Allan Stephenson, Ángel Gómez y James Diaz. La música no es arqueología ni (solo) un museo, es un árbol y está viva.

En 1974 la osx interpretó la Novena sinfonía de Beethoven, con escenografía de Fernando Vilchis y coreografía de Xavier Francis ejecutada por el Ballet Contemporáneo de Xalapa, novedad que habrá entusiasmado a unos y molestado a otros. Aquel evento acorde con los tiempos mostraba una orquesta rebosante de ideas pero que, tras bambalinas, padecía de una carencia de recursos que amenazaba su existencia; con alrededor de treinta músicos, se dividió en ensambles que se presentaban en escuelas primarias y secundarias; paradójicamente esta crisis abrió otros caminos: quizá alguno de aquellos estudiantes asiste ahora cada viernes a Tlaqná. Nunca oí a Ávila dirigir la osx pero hace poco escuché una grabación suya de 1978 como director invitado; su versión de la Primera sinfonía de Brahms no es lenta ni majestuosa, como se estilaba entonces, sino dinámica, especialmente en el Finale. Esa interpretación estaba en sinto-

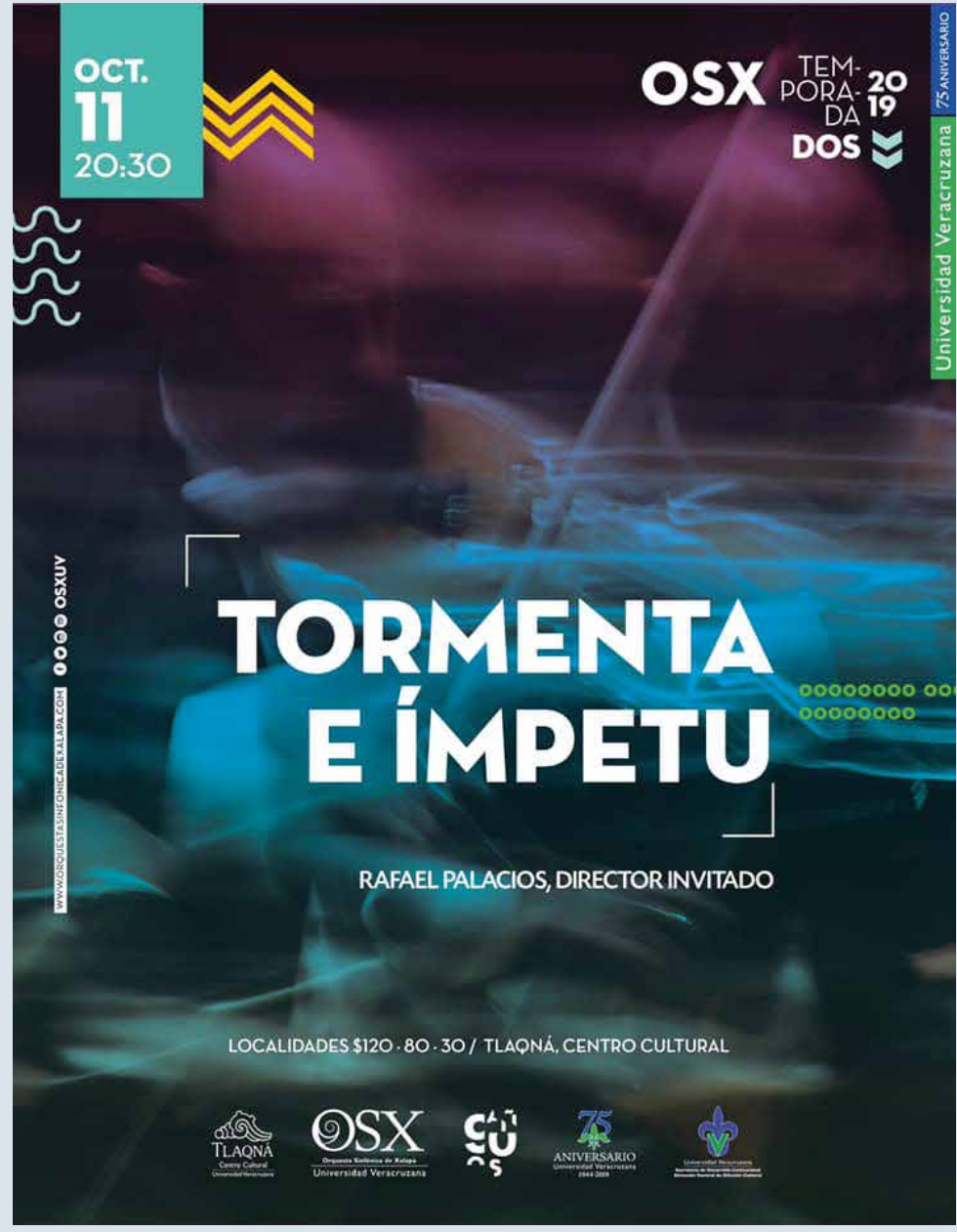

Diseño: Sinsuni E. Velasco Gutiérrez.

nía con una tradición (Weingartner, van Beinum, Jochum, Krips) que, a pesar de su prestigio, no era dominante y sería vindicada a finales de la década de 1990 por la destacada interpretación historicista que hizo Charles Mackerras. Ávila renunció a la dirección de la osx desgastado por el calvario de buscar recursos; de haberle tocado otra situación quizá ocuparía un lugar más protagónico en su historia.

Varias instituciones musicales locales estuvieron desde su origen ligadas a la osx. La Facultad de Música tiene su antecedente en la Escuela de Música, Danza y Declamación, creada en 1944 por el gobierno de Jorge Cerdán, uno de cuyos objetivos era formar músi- cos en una época en que no había suficientes en el país; en 1952 la pianista Estela Olvera Guiot fue la primera egresada en ser solista con la osx. El Coro de la UV se creó en 1950 para abordar el repertorio para coro y orquesta; la aportación de sus directores (Luis Berber, Eugenio Sleziak, Daniel Hazan) ha sido de primer orden. Varios miembros de la osx han dado y dan clases en el Centro de Iniciación Musical Infantil (CIMI, fundado en 1976) y el Instituto Superior de Música del Estado de Veracruz (ISMEV, creado en 2002), que a su vez han provisto de músicos a la osx, igual que lo han hecho, en menor medida, la Escuela Municipal de Bellas Artes de Veracruz (EMBA) y el Instituto Municipal de Bellas Ar- 
tes de Orizaba (IMBAO). El sistema musical veracruzano gira alrededor de la osx, que a su vez se nutre de él.

El 12 de abril de 2013 escuché en la Casa del Lago un recital de piano con alumnos del cimi de entre siete y doce años; unos tocaban con soltura, otros hacían un esfuerzo supremo. Para algunos familiares el recital era una costumbre, para otros un acontecimiento. Algunos padres conocían el repertorio y otros no disimulaban su sorpresa al escuchar por vez primera al niño o la niña, otros se aburrían sin remedio; había niños que, se notaba, recibían apoyo mientras que otros apenas eran tolerados. Todo era contraste: la manera de vestir, la postura corporal, el vocabulario y el acento. Recuerdo a un padre de manos callosas y ropa sencilla que poco a poco fue ganado por la música. Si el CIMI ha formado a alrededor del 20 por ciento de los músicos actuales de la osx también ha introducido la música clásica en familias que carecen de esa tradición; quizá algunas nunca se acerquen a escuchar a la osx, pero no importa; la semilla queda sembrada y la cosecha se ramifica en grupos de música popular, en coros de aficionados, en las marching bands de las secundarias (que ensayan los fines de semana en el Estadio Xalapeño y tocan arreglos del Huapango o del Danzón n. 2). El ecosistema musical explica que en las calles del centro de la ciudad sea común escuchar auténticos recitales de cualquier instrumento o que una guitarra amenice un café en Coatepec con un repertorio del Barroco a nuestros días, como si fuera lo más normal del mundo, o que muchos ciudadanos pasen por el suplicio de tener un vecino que estudia música. Escuchar a un alumno revitaliza la apreciación; oír siempre bien tocada la música (como en los discos) mecaniza su escucha, oculta que el error, y aun la catástrofe, acechan siempre.

En 1991 en el Aula Clavijero se presentaron algunos números de Don Giovanni, dirigida por Nohemí Cortés Guzmán, con Tito Tablada, Ana Luisa Méndez, Ariel Barradas, Benjamín Castro y Guadalupe Colorado, con Óscar Tarragó al piano, muy atento a los matices de la obra. El 11 de junio de 1992 escuché las Escenas infantiles de Schumann con Citlalli Guevara al piano; el 3 de septiembre de 1993, el Concierto en sol de Ravel con la osx y Édgar Dorantes como solista; el 26 de febrero de 1994, el Quinteto para piano de Schumann con Isabel Ladrón de Guevara, María de Jesús Arias (violín I), Ernesto Zamora (violín II), Tonatiuh García (viola) y Emilia Zamora (violonchelo). En el auditorio de la antigua Facultad de Música también escuché en recitales de cámara a Alain y Alexis
Fonseca, Anayeli Olivares, Tonatiuh Bazán, Elizabeth Gutiérrez, Eduardo Flores, Carlos Villareal, Tadeo Valencia, Rodrigo Álvarez, Jalil J. Eufracio y Jorge López, miembros actuales de la osx; todos eran estudiantes. Los profesores también daban recitales y el 22 de abril de 1990 en el auditorio del Museo de Antropología escuché la Sonata para violín y piano de César Franck con Ernesto Tarragó y Laura Sosa. Para la historia de la música la de cámara cuenta igual que la sinfónica, por ello esta comunidad de profesores y alumnos (ligada de una manera u otra a la osx) también ha educado musicalmente a varias generaciones.

Hay un relato (o varios) sobre la creación de la osx; el más difundido está en el libro pionero de 1994 de Sergio Dorantes y Yolanda Reyes. Está por escribirse una historia en toda regla que documente los relatos, los contraste y contextualice. Sería una historia coral que tome en cuenta a políticos (como Jorge Cerdán), a rectores (como Roberto Bravo Garzón), a autores de notas (como Jorge Vázquez Pacheco), a presidentes de los patronatos (como Adolfo Domínguez y Nicanor Moreira), a directores, concertinos, músicos, todo tipo de trabajadores, jefes de personal, diseñadores $y$, desde luego, al público.

\section{CONEXIONES}

La osx no es solo una entidad musical sino una escuela en la que los sucesivos recintos (teatro Lerdo, Teatro del Estado, Tlaqná) han funcionado de facto como aula. El 3 de diciembre de 1993 escuché la Primera sinfonía de Mahler bajo la dirección de Francisco Savín. Las notas del programa de mano comenzaban

Meiningen, abril de 1801 [...] Ajeno al estímulo de paraísos artificiales, Johann Paul Friedrich Richter se entrega por completo al dominio de aquellas alucinaciones que él mismo invoca cuando improvisa sobre el teclado [...] transfigurado gracias a la magia de su propio ritual, Jean Paul intenta fijar las huellas del espíritu en la fragilidad del pentagrama y, así, debemos entender que el cansancio lo entrega a las divinidades del sueño para que continúe su labor aquella metódica fantasía que se ha posesionado del alma del poeta [...] Jean Paul no sabe todavía -esa fría mañana de primavera- que el título elegido Das Genie será transformado en Titán. Ochenta años después, un ejemplar del libro llegará a las manos de un joven judío llamado Gustav Mahler. 


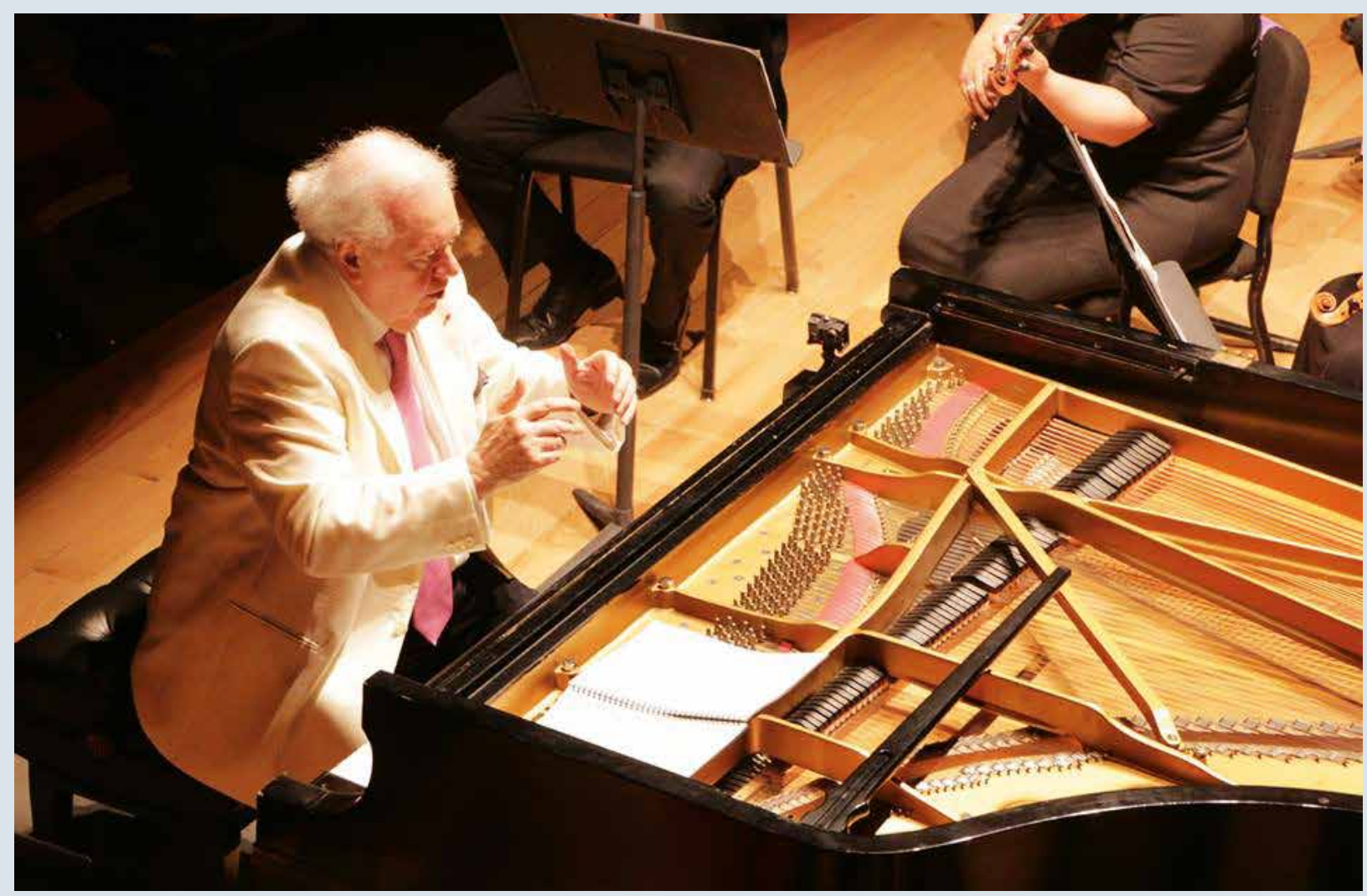

Philippe Entremont dirigiendo a la osx desde el piano, durante un concierto de Mozart, 2018. Sala Tlaqná, 2018. Foto: Omar Ramírez.

Así que Titán no era solo mi refresco predilecto en la secundaria y una luna de Júpiter sino una novela del escritor romántico Jean Paul Richter. Las notas de Guillermo Cuevas explicaban detalles técnicos y además establecían relaciones con la pintura, la literatura, la filosofía y los sucesos de la época. Aprendí que la música es un mundo en sí mismo pero también un observatorio para verlo de otra manera, por lo que esas notas eran tan importantes como la propia ejecución musical; aunque nunca me diera una clase, Cuevas es uno de mis maestros. Nidia Vincent y Mercedes Lozano, mis profesoras en la Facultad de Letras, también escribían notas de concierto. Por décadas la osx ha integrado en su proyecto las fuerzas culturales locales.

La osx es un eficaz instrumento para el conocimiento de otras culturas. Por ejemplo, en 1993 los acentos checos estaban en las obras de Bedřich Smetana y Antonín Dvořák pero también en su interpretación de la Sinfonía n. ${ }^{\circ} 1$ de Mahler, en la que hubo detalles (tercer movimiento) que le dieron un aire popular y eslavo que no tenían las dos o tres grabaciones que conocía entonces. Savín había estudiado en la Escuela Superior de la Academia de Música de Praga con Václav Smetáček (discípulo nada menos que de Václav Talich, el director checo más importante del siglo xx) y con Zuzana Růžičková, una de las clavecinistas más importantes del siglo $\mathrm{xx}$, quien hizo la primera grabación integral de la obra para teclado de J. S. Bach. En 1992 Sergio Pitol había publicado el ensayo "Paseo por las literaturas de Praga" en la Revista de la Universidad de México y su prólogo a Las aventuras del buen soldado Schveik durante la guerra mundial, de Jaroslav Hašek; en 1993 el escritor llegó a Xalapa hablando con entusiasmo de la Filarmónica Checa y de Karel Ančerl, su director, por quienes sentía una devoción que rayaba en el culto; uno de sus discos predilectos era el de la sinfonía Titán (grabación de 1964) cuyos acentos se parecían a los que puso Savín. Así, en una pequeña ciudad de provincia se podía conocer la cultura bohemia sin pasar por sus lugares comunes o lo meramente libresco. La tradición sigue: el 23 de junio de 2017, la osx tocó el ciclo de poemas sinfónicos Má Vlast [Mi patria] de Smetana. La flautista principal de la osx, Lenka Smolcakova, egresó del Conservatorio de Praga. Hay también una tradición norteamericana, polaca, rusa ... Cuando Lanfranco Marcelletti Jr. dirigió el Stabat Mater de Rossini (23 de marzo de 2018), lo hizo como alumno del más eminente especialista en ese compositor del siglo xx, Alberto Zedda. El concertino, Mikhail Medvid, es discípulo de uno de los violinistas más importantes del mismo siglo, el ruso David Oistrakh. 


\section{CÁNDIDO}

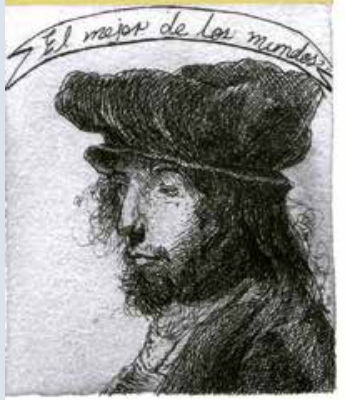

Prólogo de Francisco Rebolledo
AsÍ HABLABA

ZARATUSTRA

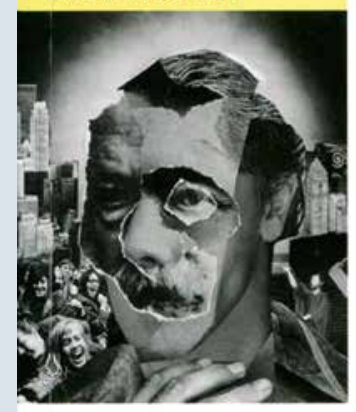

Prólogo de Julio Quesada
Friedrich Nietzsche

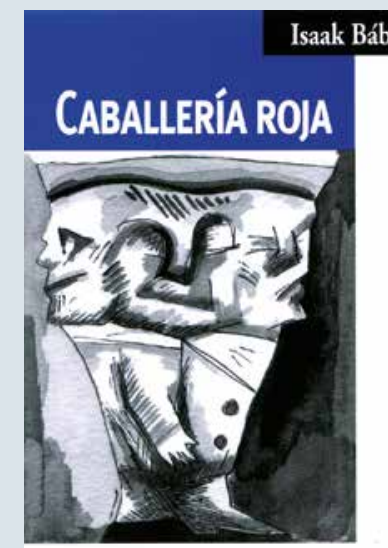

Prólogo de Agustín del Moral Tejeda
La osX no es de Xalapa, está en Xalapa, la representa porque su raíz es la misma: se nutre de quienes han venido de muchas partes, atraídos por la Universidad Veracruzana. La orquesta es un caleidoscopio.

Una orquesta sinfónica es un organismo repleto de vasos comunicantes.

Durante un concierto podría pensarse que solo importa la música pero los acordes traspasan las paredes. La osx interpretó el 16 de noviembre de 2018 Así hablaba Zaratustra de Richard Strauss; quien haya leído el libro de Friedrich Nietzsche oirá de otra manera el poema sinfónico, o podrá incluso considerarlo secundario. El 23 de febrero de 2018 la osx tocó la Sinfonía n. ${ }^{\circ} 11$, El año 1905, de Shostakovich, que describe la masacre de civiles perpetrada por el régimen zarista que desencadenó una protorrevolución; la destrucción y los excesos de la guerra civil son descritos en los relatos de Caballería roja de Isaak Babel. En 2016 en 2017, la 85; en 2018, la 104, Londres. ¿Hay mejor manera de entender la Ilustración -su confianza en la razón, su voluntad de claridad, su humor- que a través de estas obras? Sí: la lectura de Cándido de Voltaire. Los tres libros -números 25, 51 y 35 de la Biblioteca del Universitario de la Uv- muestran que la música está íntimamente relacionada con la cultura y la historia, de las que forman parte a través de una permanente tensión: ilustra ideas y tendencias de la época al tiempo que permanece como reducto de la creatividad individual.

En los años de Tiananmén, las Revoluciones de Terciopelo, la caída de la uRss y los cambios inesperados en México (que llegaron a un punto crítico en 1994), la osx programó La canción de los bosques de Shostakovich; algunos de sus miembros provenientes de Europa central (entonces Europa del Este) lo objetaron; se trataba de una loa a Stalin, autor de crímenes de guerra como el de Katyn y otras atrocidades. Esas y otras polémicas forman parte del día a día de una orquesta. Ahora el jazz está plenamente aceptado en Xalapa pero cuando Édgar Dorantes pasó de la música clásica al jazz hubo sorpresa y hasta reprobación. El 8 de febrero de 2019 la osx tocó la Sinfonía $n^{\circ} .4$ de Beethoven, sin mayor novedad ... aparentemente, pues la interpretación estuvo teñida de criterios historicistas (tiempos más rápidos, texturas más claras, ciertos acentos) que estaban muy lejos de utilizarse 
en Xalapa en los años noventa, cuando incluso en las metrópolis levantaban oposición. En la música todo es debate, por supuesto.

\section{CAMBIDS}

Cada ciudad que tiene una orquesta establece una relación propia con ella. En las metrópolis siempre hay varias (Londres, Berlín, Nueva York, Buenos Aires, Ciudad de México), cada una con su público y su ámbito de influencia. Las ciudades pequeñas comúnmente tienen una sola orquesta y su vínculo con ella es más intenso. El caso de Xalapa es curioso, hay casi una decena (osx, Sinfónica Juvenil del Ismev, Filarmonía, Filarmónica de Xalapa, Orquesta de Cámara de Xalapa, Orquesta de la Facultad de Música, Orquesta de Música Popular, Orquesta de Guitarras, Orquesta del Ivec, Banda Sinfónica del Estado de Veracruz), y aunque muchas no tengan una temporada regular todas forman parte de la vida musical; quizá en América Latina ninguna otra ciudad tenga, en proporción a su tamaño, tantas. El concierto del 7 de junio de 2019 en el Teatro del Estado con la Orquesta del ISMEv lo dice todo: esta tiene el nivel promedio de muchas orquestas de provincia, pero en Xalapa el desarrollo musical ha sido tal que ahora hay un nuevo teatro y la agrupación decana tiene mayor nivel. En marzo de 2019 la osx tocó El anillo sin palabras, el arreglo de Lorin Maazel de El anillo de los nibelungos de Wagner; apenas ocho días después la Sinfonía n. 2 de Mahler y un par de semanas más tarde la Misa solemnis de Beethoven (con la destacada participación en ambas del Coro de la uv, bajo la dirección de Noel Josafat García Melo). Antaño, uno de estos conciertos habría sido el número estelar de la temporada; ahora son ordinarios. Tener una programación así es una proeza para una ciudad de provincia en América Latina. En medio de una profunda crisis política, económica y social, Xalapa se volvió un centro musical nacional cuyo símbolo es Tlaqná; esto, francamente, roza el milagro.

No todo está hecho, entre más profesional se vuelve la vida musical, más evidentes se hacen carencias, puntos débiles y vacíos. En varios conciertos con programación innovadora la asistencia ha sido parca. Así como Herrera de la Fuente presentó en los años setenta por primera vez la integral de las sinfonías de
Beethoven, es hora de que en Xalapa se interprete una integral de sus obras de cámara, género que requiere su institucionalización local; en ello la Sala Anexa de Tlaqná puede ser central así como en la consolidación de la osx como centro de educación continua: conferencias, cursos, charlas (Música y Literatura, ciclo impartido por Guillermo Cuevas y Axel Juárez, es un proyecto exitoso). La ópera podría tener en Xalapa un desarrollo extraordinario. Falta también impulsar la crítica y el periodismo musical. Tlaqná es un punto de partida para alcanzar metas que harían de la ciudad una de las capitales musicales del continente.

El país ha cambiado drásticamente en el último medio siglo pero su canon musical clásico es básicamente el que configuró el nacionalismo revolucionario entre 1920 y 1950 . No deben dejar de tocarse obras de Moncayo, Chávez y Revueltas sino interpretarse otras de ellos y de Julián Carrillo, José Rolón y Candelario Huízar, entre muchos compositores. Hay obras maestras prácticamente desconocidas. La OSX puede jugar un papel protagónico en la instauración de un canon para el siglo XXI, más ecléctico, más preciso, más justo.

La osx no es de Xalapa, está en Xalapa, la representa porque su raíz es la misma: se nutre de quienes han venido de muchas partes, atraídos por la Universidad Veracruzana. La orquesta es un caleidoscopio, cada músico tiene detrás miles de horas de estudio, la guía de sus maestros, sus viajes y otros aprendizajes; cada uno (con su técnica, su sonido, su musicalidad, que se modifica con el tiempo) es un río que desemboca en el océano de la orquesta. Su solidez actual no proviene solo de que cuenta con un firme apoyo institucional sino también de su estrecha relación con el público, lo que le otorga lo más importante: una amplia legitimidad social. Damos las gracias a todos, absolutamente a todos los músicos que la forman y han formado parte de ella. Su dedicación y magisterio son invaluables. LPyH

Alfonso Colorado es investigador en el Centro de Estudios de la Cultura y la Comunicación de la uv y ensayista. 